\title{
A Simple Predictive Method of Critical Flicker Detection for Human Healthy Precaution
}

\author{
Goh Zai Peng, Mohd Amran Mohd Radzi, Hashim Hizam, and Noor Izzri Abdul Wahab \\ Department of Electrical and Electronic Engineering, Faculty of Engineering, Universiti Putra Malaysia, \\ 43400 Serdang, Selangor, Malaysia \\ Correspondence should be addressed to Goh Zai Peng; zaipeng5987@gmail.com
}

Received 29 June 2015; Revised 14 September 2015; Accepted 15 September 2015

Academic Editor: Kalyana C. Veluvolu

Copyright (C) 2015 Goh Zai Peng et al. This is an open access article distributed under the Creative Commons Attribution License, which permits unrestricted use, distribution, and reproduction in any medium, provided the original work is properly cited.

Interharmonics and flickers have an interrelationship between each other. Based on International Electrotechnical Commission (IEC) flicker standard, the critical flicker frequency for a human eye is located at $8.8 \mathrm{~Hz}$. Additionally, eye strains, headaches, and in the worst case seizures may happen due to the critical flicker. Therefore, this paper introduces a worthwhile research gap on the investigation of interrelationship between the amplitudes of the interharmonics and the critical flicker for $50 \mathrm{~Hz}$ power system. Consequently, the significant findings obtained in this paper are the amplitudes of two particular interharmonics are able to detect the critical flicker. In this paper, the aforementioned amplitudes are detected by adaptive linear neuron (ADALINE). After that, the critical flicker is detected by substituting the aforesaid amplitudes to the formulas that have been generated in this paper accordingly. Simulation and experimental works are conducted and the accuracy of the proposed algorithm which utilizes ADALINE is similar, as compared to typical Fluke power analyzer. In a nutshell, this simple predictive method for critical flicker detection has strong potential to be applied in any human crowded places (such as offices, shopping complexes, and stadiums) for human healthy precaution purpose due to its simplicity.

\section{Introduction}

In the current century, the voltage flicker happens mainly due to the utilization of nonlinear loads such as arc furnace and motor drive [1]. Voltage flicker is a type of voltage fluctuation with certain frequency and it causes visual sensation made by an unsteadiness luminance (light) that fluctuates with time which can cause headache [2]. At present, flicker severity measurement based on IEC flickermeter is widely used in the industries [3]. Short Term Perceptibility $\left(P_{\mathrm{st}}\right)$ and Long Term Perceptibility $\left(P_{\mathrm{lt}}\right)$ are assessed in the IEC flickermeter via instantaneous flicker sensation $\left(P_{\text {inst }}\right) . P_{\text {st }}$ and $P_{\text {lt }}$ are referred to as a recorded data of $P_{\text {inst }}$ under observation of 10 minutes and 2 hours, respectively. A number of research works have been carried out to improve accuracy of the flickermeter [4, 5]. Some researchers did investigation on reducing the observation time of $P_{\text {st }}$ [6]. Many of the researchers proposed their methods for flicker mitigation in the power system $[7,8]$.
Furthermore, flicker detection has been carried out based on wavelet Fourier transform [9], atomic method [10], new modified S-transform algorithm [11], and Chirp-z transform [12].

Based on IEC standard, the critical flicker frequency which is the most sensitive to human eyes is located at $8.8 \mathrm{~Hz}$ [3]. To be more precise, when the supplied voltage consists of flicker frequency of $8.8 \mathrm{~Hz}$, it will cause the lamp to flick with $8.8 \mathrm{~Hz}$. Additionally, eye strains, headaches, and in the worst case seizures may happen due to the aforementioned lamp flicking [13]. Although this type of flicker causes such significant impact; however, to date, there is no work yet on developing and implementing algorithm to detect critical flicker.

Therefore, this worthwhile research work is to propose a simple predictive method for critical flicker detection (CFD) for human health awareness. Due to the simplicity of the proposed algorithm, it should have strong potential to be applied later in offices, shopping complexes, and stadiums for human comfy. 
From a mathematical point of view, a flicker waveform may inherently give some significant changes on the amplitudes of the particular interharmonics [14]. Moreover, the interrelationship between interharmonics and flicker had been provoked due to the concern of proper power quality (PQ) control [2, 15-18]. Therefore, CFD can be done by detecting the particular interharmonics' amplitudes.

A number of signal processing algorithms based on different techniques for interharmonics detection such as fast Fourier transform (FFT), short-time Fourier transform (STFT) [19], and spectrogram [20] have been reported over the past years [21]. STFT and spectrogram algorithms are generated based on FFT. Interharmonics detection based on FFT is widely used in the industries [22]. However, the operation of the FFT may lead to inaccurate result due to phenomena of aliasing [23], leakage [24], and picket fence effects [24].

As an alternative, presently, artificial intelligent algorithms have received special attention from the researchers due to their simplicity, generalization and learning ability. Based on their advantages, the interharmonics are able to be estimated by several artificial intelligent algorithms such as least absolute value (LAV) [25], Kalman filter (KF) [26], adaptive linear neuron (ADALINE) [27], and simulated annealing (SA) [28]. The main advantage of artificial intelligent algorithms (especially ADALINE) is that they can estimate the amplitude and phase rapidly with the condition that the frequencies of the measurement signal need to be initially defined. Specifically, for this work, the critical interharmonics' frequencies are already defined initially based on calculation as further explained in the following section. Therefore, ADALINE is merited as to be utilized in the proposed algorithm as compared to signal processing methods.

This paper presents a work on a simple predictive method of CFD based on interharmonics via ADALINE for human healthy precaution. The organization of this paper is as follows. In Section 2, critical explanation of the relationship between interharmonics and flicker is discussed. After that, the critical flicker frequency is summarized in Section 3. The background of the ADALINE is explained in Section 4. The description of the proposed algorithm is presented in Section 5. Sections 6 and 7 present the simulation and experimental works, respectively, to further verify performance of the proposed algorithm. Finally, the conclusion is presented in Section 8.

\section{Relationship between Interharmonics and Flicker}

Basically, the appearance of interharmonics in a power system may lead to modulated waveform. The fluctuation frequency of the instantaneous voltage is considered as flicker frequency. The flicker frequency [14], $f_{\text {flicker }}$, can be calculated by

$$
f_{\text {flicker }}=\left|f_{\mathrm{IH}}-f_{\mathrm{f}}\right|,
$$

where $f_{\mathrm{IH}}$ is the interharmonic frequency and $f_{\mathrm{f}}$ is the fundamental frequency of the power system. For example, if the flicker frequency is defined as $3 \mathrm{~Hz}$ and the fundamental frequency is $50 \mathrm{~Hz}$, the interharmonics are $47 \mathrm{~Hz}$ and $53 \mathrm{~Hz}$. Practically, the flicker may present due to a single interharmonic $(47$ or $53 \mathrm{~Hz}$ ) or a pair of interharmonics $(47$ and $53 \mathrm{~Hz}$ together). Starting from fundamental principle, the relationship is investigated by deriving the formula of flicker produced by single interharmonic. The following equation shows the relation between exponential, sine, and cosine functions:

$$
A e^{j \omega t}=A(\cos (\omega t)+j \sin (\omega t))
$$

where $A$ and $\omega$ are represented as amplitude and particular angular frequency, respectively. The following equation represents the instantaneous voltage with combination of single interharmonic $\left(v_{1}(t)\right)$ in exponential form:

$$
v_{1}(t)=\alpha_{1} e^{j \omega_{1} t}+\alpha_{2} e^{j \omega_{2} t}
$$

where $\alpha_{1}$ and $\omega_{1}$ are represented as fundamental amplitude and its angular frequency. Meanwhile, $\alpha_{2}$ and $\omega_{2}$ are symbolized as the interharmonic amplitude and its angular frequency.

After the elaboration,

$$
v_{1}(t)=e^{j \omega_{1} t}\left(\alpha_{1}+\alpha_{2} e^{j\left(\omega_{2}-\omega_{1}\right) t}\right)
$$

The $e^{j \omega_{1} t}$ is represented as factorized exponential form of fundamental frequency. The instantaneous amplitude is summarized as $\alpha_{1}+\alpha_{2} e^{j\left(\omega_{2}-\omega_{1}\right) t}$. Somehow, the instantaneous amplitude can be calculated as follows:

$$
\operatorname{Amp}_{1 H}=\left|\alpha_{1}+\alpha_{2} e^{j\left(\omega_{2}-\omega_{1}\right) t}\right|
$$

The equation can be rewritten as follows:

$$
\begin{aligned}
& \text { Amp }{ }_{1 H} \\
& \quad=\left|\alpha_{1}+\alpha_{2} \cos \left(\omega_{2}-\omega_{1}\right) t+j \alpha_{2} \sin \left(\omega_{2}-\omega_{1}\right) t\right|,
\end{aligned}
$$

where $\alpha_{1}+\alpha_{2} \cos \left(\omega_{2}-\omega_{1}\right) t$ and $\alpha_{2} \sin \left(\omega_{2}-\omega_{1}\right) t$ are represented as real and imaginary parts, respectively. In order to calculate the amplitude, the aforementioned real and imaginary parts are set as modulus as follows:

$$
\begin{aligned}
& \text { Amp } \cdot 1 H \\
& =\sqrt{\left[\alpha_{1}+\alpha_{2} \cos \left(\omega_{2}-\omega_{1}\right) t\right]^{2}+\left[\alpha_{2} \sin \left(\omega_{2}-\omega_{1}\right) t\right]^{2}} .
\end{aligned}
$$

Thus,

$$
\mathrm{Amp}_{1 H}=\sqrt{\alpha_{1}^{2}+\alpha_{2}{ }^{2} \cos ^{2}\left(\omega_{2}-\omega_{1}\right) t+2 \alpha_{1} \alpha_{2} \cos \left(\omega_{2}-\omega_{1}\right) t+\alpha_{2}^{2} \sin ^{2}\left(\omega_{2}-\omega_{1}\right) t}
$$




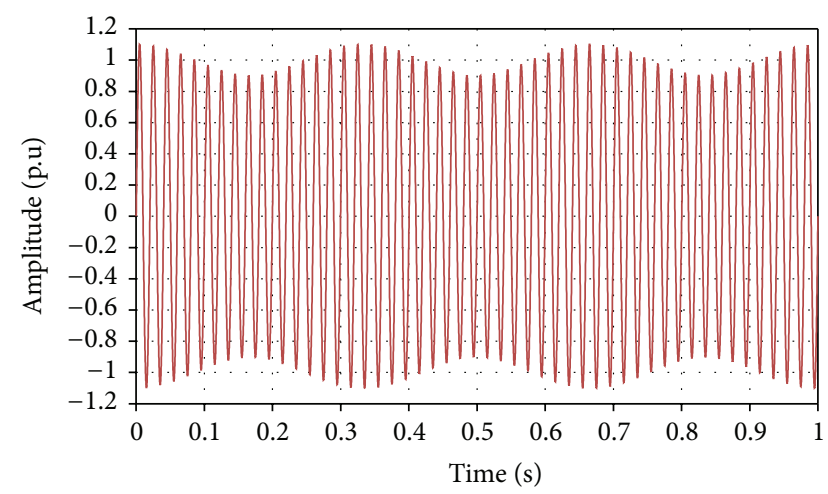

(a)

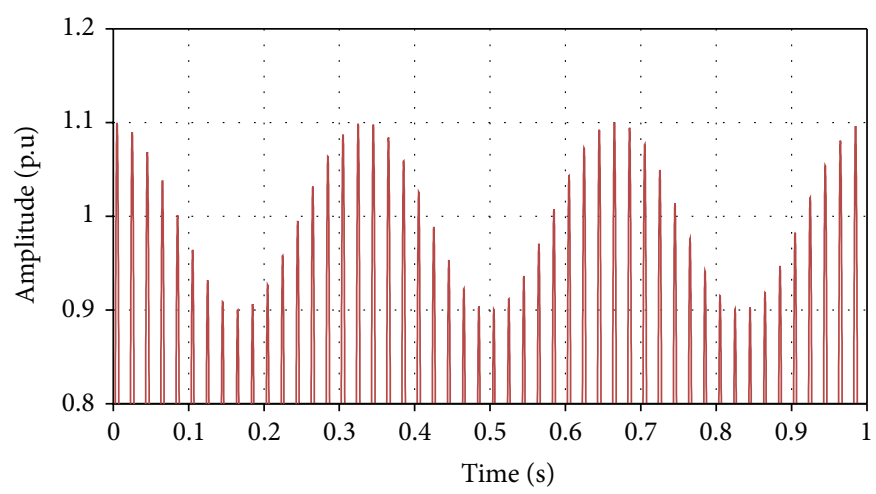

(b)

FIGURE 1: Flicker waveform caused by single interharmonic: (a) zoom-out version and (b) zoom-in version.

Finally, the instantaneous amplitude is summarized as follows:

$$
\mathrm{Amp}_{1 H}=\sqrt{\alpha_{1}^{2}+\alpha_{2}^{2}+2 \alpha_{1} \alpha_{2} \cos \left(\omega_{2}-\omega_{1}\right) t} .
$$

In order to estimate the maximum and minimum of the instantaneous voltage, the $\cos \left(\omega_{2}-\omega_{1}\right) t$ is substituted to 1 and -1 , respectively. Therefore, the formulas for maximum and minimum of the instantaneous voltage are shown as follows:

$$
\begin{aligned}
& \operatorname{Amp}_{1 H} \max =\sqrt{\alpha_{1}{ }^{2}+\alpha_{2}{ }^{2}+2 \alpha_{1} \alpha_{2}(1)} \\
& \text { Amp } \cdot_{1 H} \min =\sqrt{\alpha_{1}{ }^{2}+\alpha_{2}{ }^{2}+2 \alpha_{1} \alpha_{2}(-1)} .
\end{aligned}
$$

Thus, as to evaluate the severity of the flicker, relative fluctuation $(\Delta v / v)$ is needed to be calculated by using the following formula:

$$
\frac{\Delta v}{v}=\frac{\mathrm{Amp}_{1 H} \cdot \max -\mathrm{Amp}_{1 H} \cdot \min }{\alpha_{1}} \times 100 .
$$

In relation to $50 \mathrm{~Hz}$ voltage supply, it consists of single interharmonic of $47 \mathrm{~Hz}$ with 0.1 p.u. $\left(\alpha_{2}\right)$, as shown in Figure 1. In more detail, Figures 1(a) and 1(b) show the zoom-out and zoom-in versions of the waveform, respectively. Based on Figure 1(b), flicker frequency of $3 \mathrm{~Hz}$ can be seen obviously. At the same time, the flicker frequency can be calculated manually via (1). Based on Figure 1, the maximum and minimum of the fluctuation voltage are 1.1 and 0.9 p.u., respectively. Assume the amplitude of fundamental $\left(\alpha_{1}\right)$ and interharmonic $\left(\alpha_{2}\right)$ are already determined, which are 1 and 0.1 p.u., respectively. After that, the maximum and minimum of the instantaneous voltage can be obtained by (10), which are 1.1 and 0.9 p.u., respectively. The values that are calculated via (10) are proven to be similar to the maximum and minimum of the instantaneous values in Figure 1. Furthermore, the $\Delta v / v$ can be calculated by (11) and the $\Delta v / v$ for Figure 1 as can be seen obviously is $20 \%$. Based on the explanation above, the amplitudes of fundamental $\left(\alpha_{1}\right)$ and interharmonic $\left(\alpha_{2}\right)$ are the key values to identify $\Delta v / v$.
In more practical situation, flicker waveform may occur due to a pair of interharmonics. Therefore, the derivation of formula for aforementioned situation is shown as follows:

$$
v_{2}(t)=\alpha_{3} e^{j \omega_{3} t}+\alpha_{1} e^{j \omega_{1} t}+\alpha_{2} e^{j \omega_{2} t} .
$$

The $v_{2}(t), \alpha_{1}$, and $\omega_{1}$ are represented as the instantaneous voltage for a pair of interharmonics, fundamental amplitude, and angular frequency (fundamental), respectively. Meanwhile, the $\alpha_{2}$ and $\omega_{2}$ are symbolized as the first interharmonic amplitude and its angular frequency. Finally, the $\alpha_{3}$ and $\omega_{3}$ are represented as the second interharmonic amplitude and its angular frequency. The relationship of $\omega$ is assumed as $\omega_{3}<\omega_{1}<\omega_{2}$.

After that, the aforementioned instantaneous voltage becomes

$$
v_{2}(t)=e^{j \omega_{1} t}\left(\alpha_{1}+\alpha_{2} e^{j\left(\omega_{2}-\omega_{1}\right) t}+\alpha_{3} e^{j\left(\omega_{3}-\omega_{1}\right) t}\right) .
$$

The $e^{j \omega_{1} t}$ is represented as factorized exponential form of fundamental frequency. The amplitude is represented as $\alpha_{1}+$ $\alpha_{2} e^{j\left(\omega_{2}-\omega_{1}\right) t}+\alpha_{3} e^{j\left(\omega_{3}-\omega_{1}\right) t}$. Therefore, the amplitude can be calculated as follows:

$$
A m p \cdot{ }_{2 H}=\left|\alpha_{1}+\alpha_{2} e^{j\left(\omega_{2}-\omega_{1}\right) t}+\alpha_{3} e^{j\left(\omega_{3}-\omega_{1}\right) t}\right| .
$$

After the expansion,

$$
\begin{aligned}
& \text { Amp }_{2 H}=\mid \alpha_{1}+\alpha_{2} \cos \left(\omega_{2}-\omega_{1}\right) t \\
& \quad+j \alpha_{2} \sin \left(\omega_{2}-\omega_{1}\right) t+\alpha_{3} \cos \left(\omega_{3}-\omega_{1}\right) t \\
& \quad+j \alpha_{3} \sin \left(\omega_{3}-\omega_{1}\right) t \mid .
\end{aligned}
$$

In order to calculate the amplitude, the aforementioned real and imaginary parts are set as modulus as follows:

$$
\begin{aligned}
& \text { Amp } \cdot 2 H \\
& \quad=\left[\left[\alpha_{1}+\alpha_{2} \cos \left(\omega_{2}-\omega_{1}\right) t+\alpha_{3} \cos \left(\omega_{3}-\omega_{1}\right) t\right]^{2}\right. \\
& \left.\quad+\left[\alpha_{2} \sin \left(\omega_{2}-\omega_{1}\right) t+\alpha_{3} \sin \left(\omega_{3}-\omega_{1}\right) t\right]^{2}\right]^{1 / 2} .
\end{aligned}
$$




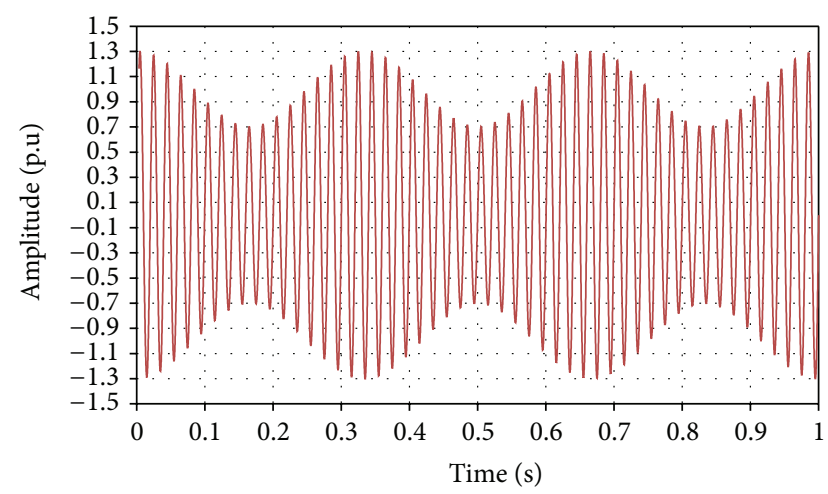

(a)

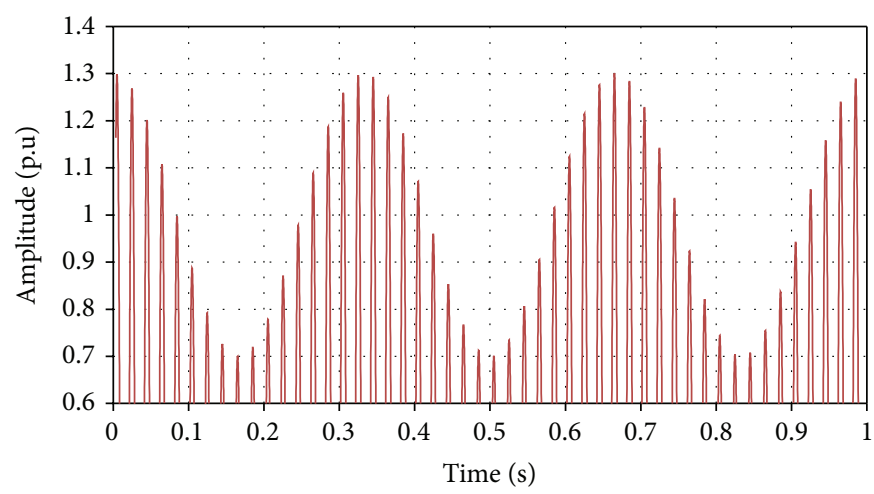

(b)

FIGURE 2: Flicker waveform caused by a pair of interharmonics: (a) zoom-out version and (b) zoom-in version.

Further elaboration is

$$
\begin{aligned}
& \text { Amp. }_{2 H}=\left[2 \alpha_{1} \alpha_{2} \cos \left(\omega_{2}-\omega_{1}\right) t\right. \\
& \quad+2 \alpha_{1} \alpha_{3} \cos \left(\omega_{3}-\omega_{1}\right) t \\
& \quad+2 \alpha_{2} \alpha_{3} \cos \left(\omega_{2}-\omega_{1}\right) t \cos \left(\omega_{3}-\omega_{1}\right) t+\alpha_{1}{ }^{2} \\
& \quad+\alpha_{2}{ }^{2} \cos ^{2}\left(\omega_{2}-\omega_{1}\right) t+\alpha_{3}{ }^{2} \cos ^{2}\left(\omega_{3}-\omega_{1}\right) t \\
& \quad+\alpha_{2}{ }^{2} \sin ^{2}\left(\omega_{2}-\omega_{1}\right) t \\
& \quad+2 \alpha_{2} \alpha_{3} \sin \left(\omega_{2}-\omega_{1}\right) t \sin \left(\omega_{3}-\omega_{1}\right) t \\
& \left.\quad+\alpha_{3}{ }^{2} \sin ^{2}\left(\omega_{3}-\omega_{1}\right) t\right]^{1 / 2} .
\end{aligned}
$$

Since

$$
\begin{aligned}
\omega_{3} & \prec \omega_{1} \prec \omega_{2}, \\
\omega_{3}-\omega_{1} & =\omega_{2}-\omega_{1},
\end{aligned}
$$

then,

$$
\begin{aligned}
& \text { Amp. }{ }_{2 H}=\left[2 \alpha_{1} \alpha_{2} \cos \left(\omega_{2}-\omega_{1}\right) t\right. \\
& \quad+2 \alpha_{1} \alpha_{3} \cos \left(\omega_{3}-\omega_{1}\right) t+2 \alpha_{2} \alpha_{3} \cos ^{2}\left(\omega_{2}-\omega_{1}\right) t \\
& +\alpha_{1}{ }^{2}+\alpha_{2}{ }^{2} \cos ^{2}\left(\omega_{2}-\omega_{1}\right) t+\alpha_{3}{ }^{2} \cos ^{2}\left(\omega_{3}-\omega_{1}\right) t \\
& \quad+\alpha_{2}{ }^{2} \sin ^{2}\left(\omega_{2}-\omega_{1}\right) t+2 \alpha_{2} \alpha_{3} \sin ^{2}\left(\omega_{2}-\omega_{1}\right) t \\
& \left.\quad+\alpha_{3}{ }^{2} \sin ^{2}\left(\omega_{3}-\omega_{1}\right) t\right]^{1 / 2} .
\end{aligned}
$$

By simplifying using trigonometry identity,

$$
\begin{aligned}
& \text { Amp. }_{2 H}=\left[2 \alpha_{1} \alpha_{2} \cos \left(\omega_{2}-\omega_{1}\right) t\right. \\
& \quad+2 \alpha_{1} \alpha_{3} \cos \left(\omega_{3}-\omega_{1}\right) t+2 \alpha_{2} \alpha_{3}+\alpha_{1}{ }^{2}+\alpha_{2}{ }^{2} \\
& \left.+\alpha_{3}{ }^{2}\right]^{1 / 2} .
\end{aligned}
$$

Therefore, the simplified version is

$$
\begin{aligned}
& \text { Amp. }{ }_{2 H} \\
& =\sqrt{\left[2 \alpha_{1}\left(\alpha_{2}+\alpha_{3}\right) \cos \left(\omega_{2}-\omega_{1}\right) t+2 \alpha_{2} \alpha_{3}+\alpha_{1}{ }^{2}+\alpha_{2}{ }^{2}+\alpha_{3}{ }^{2}\right]} .
\end{aligned}
$$

The maximum of the instantaneous voltage is

$$
\begin{aligned}
& \operatorname{Amp}_{\cdot 2 H} \max \\
& \quad=\sqrt{\left[2 \alpha_{1}\left(\alpha_{2}+\alpha_{3}\right)(1)+2 \alpha_{2} \alpha_{3}+\alpha_{1}{ }^{2}+\alpha_{2}{ }^{2}+\alpha_{3}{ }^{2}\right]} .
\end{aligned}
$$

The minimum of the instantaneous voltage is

$$
\begin{aligned}
& \text { Amp. }{ }_{2 H} \min \\
& =\sqrt{\left[2 \alpha_{1}\left(\alpha_{2}+\alpha_{3}\right)(-1)+2 \alpha_{2} \alpha_{3}+\alpha_{1}{ }^{2}+\alpha_{2}{ }^{2}+\alpha_{3}{ }^{2}\right]} .
\end{aligned}
$$

The maximum and minimum of the instantaneous voltage can be calculated by substituting the $\cos \left(\omega_{2}-\omega_{1}\right) t$ to 1 and -1 , respectively. In another application of $50 \mathrm{~Hz}$ voltage supply, where it consists of interharmonics of $47 \mathrm{~Hz}\left(\omega_{3}\right)$ with 0.1 p.u. $\left(\alpha_{3}\right)$ and $53 \mathrm{~Hz}\left(\omega_{2}\right)$ with 0.2 p.u. $\left(\alpha_{2}\right)$, the flicker waveform is shown in Figure 2. Based on Figure 2, the maximum and minimum of the instantaneous voltage are 1.3 and 0.7 p.u., respectively. Assume the amplitudes of first interharmonic $\left(\alpha_{3}\right)$, fundamental $\left(\alpha_{1}\right)$, and second interharmonic $\left(\alpha_{2}\right)$ are already determined, which are $0.1,1$, and 0.2 p.u., respectively. The maximum and minimum of the instantaneous voltages can be calculated by (22) and (23), which are 1.3 and 0.7 p.u., respectively. Therefore, the formulas that are generated in this paper ((22) and (23)) are proven to be correct via comparing the calculation's values and the values in Figure 2.

For Figure 2, the relative fluctuation voltage $(\Delta v / v)$ is

$$
\frac{\Delta v}{v}=\frac{\mathrm{Amp}_{2 H} \cdot \mathrm{max}-\mathrm{Amp}_{2 H} \cdot \mathrm{min}}{\alpha_{1}} \times 100 .
$$

The calculated value is $60 \%$. Again, the amplitudes of fundamental $\left(\alpha_{1}\right)$ and two interharmonics $\left(\alpha_{2}\right.$ and $\left.\alpha_{3}\right)$ are crucial to identify $\Delta v / v$.

To recap, the voltage flicker happens mainly due to overload condition. From a mathematical point of view, any generated flicker may produce significant effect to the amplitudes of the particular inter-harmonics [14]. Therefore, the relationship between interharmonics and flicker frequency is discussed clearly above. In addition, the formula for maximum and minimum of instantaneous voltage and relative fluctuation voltage is being discussed too. Finally, the amplitudes 


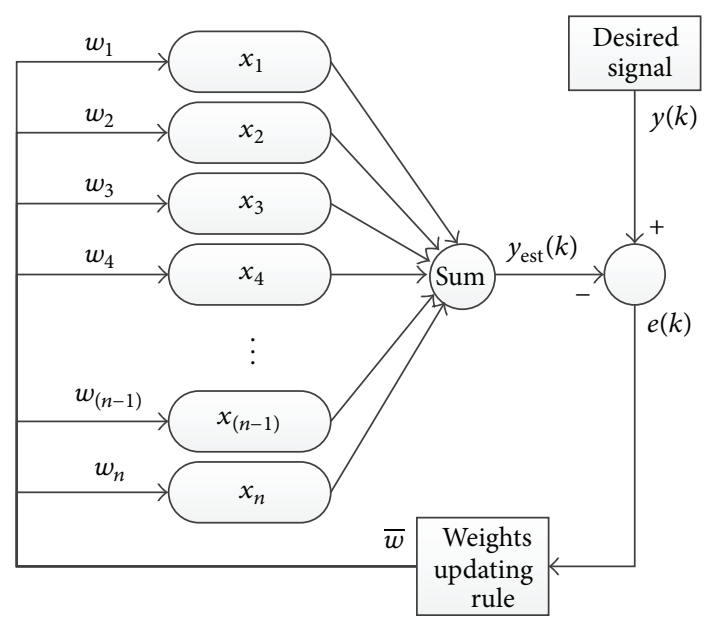

FIGURE 3: Block diagram of the ADALINE configuration.

of fundamental $\left(\alpha_{1}\right)$ and two interharmonics $\left(\alpha_{2}\right.$ and $\left.\alpha_{3}\right)$ are found to be crucial in order to identify $\Delta v / v$. The usage of $\Delta v / v$ will be discussed in the next section.

\section{Critical Flicker Frequency}

Based on IEC standard, the critical flicker frequency which is the most sensitive to human eyes is located at $8.8 \mathrm{~Hz}$ sinusoidal wave with relative fluctuation voltage $(\Delta v / v)$ of $0.25 \%$ [3]. To be more precise, when the supplied voltage consists of flicker frequency of $8.8 \mathrm{~Hz}$ sinusoidal wave with $\Delta v / v$ of $0.25 \%$, it will cause the lamp to flick with $8.8 \mathrm{~Hz}$ and it may cause human headache. From a mathematical point of view, any flicker waveform may increase the amplitudes of the particular interharmonics [14]. Based on (1), when the critical flicker $(8.8 \mathrm{~Hz})$ happens, it will cause amplitudes of $41.2 \mathrm{~Hz}(50-8.8)$ and $58.8 \mathrm{~Hz}(50+8.8)$ to increase indirectly for $50 \mathrm{~Hz}$ power system. As discussed above, detection of amplitudes for $41.2,50$, and $58.8 \mathrm{~Hz}$ is crucial to identify the maximum and minimum of the instantaneous voltage so that the $\Delta v / v$ can be calculated precisely. If the $\Delta v / v$ is greater than $0.25 \%$, the critical flicker will be detected. Last but not least, eye strains, headaches, and in the worst case seizures [13] may happen due to the critical voltage flicker. Therefore, a simple predictive method for CFD is needed for human health awareness.

\section{Background of ADALINE}

ADALINE is operated upon on learning rule and it can learn accurately with multiple loops by reducing the error between the estimation and input signals [29]. Figure 3 shows structure of the ADALINE. The desired signal $y(k)$ can be represented as Fourier series equation, or

$$
y(k)=\sum_{n=1,2,3, \ldots}^{N} A_{n} \sin \left(n k \omega t_{s}+\theta_{n}\right)
$$

After being simplified by trigonometry identity,

$$
y(k)=\sum_{n=1,2,3, \ldots}^{N} w_{1 n} \sin \left(n k \omega t_{s}\right)+w_{2 n} \cos \left(n k \omega t_{s}\right) \text {. }
$$

The formula of weights updating rule is

$$
w(k+1)=w(k)+\frac{\alpha e(k) x(k)}{x^{T}(k) x(k)},
$$

where $\alpha$ is the learning rate, $x(k)$ is the sine and cosine vector for reference signal, $e(k)$ is the error between desired signal $(y(k))$ and estimation $\left(y_{\text {est }}(k)\right)$ signal, and $w(k)$ is the estimation amplitude for $x(k)$.

First, the $w(k)$ in the weights updating rule starts with zero (initial value) and a large value of error occurs at the first iteration. After some number of iterations, the $e(k)$ will be lesser since the estimation signal will be almost similar to the desired signal. The learning rate is the heart of the weights updating rule as it can control the learning speed of the system. Thus, a suitable learning rate is needed to be determined. A large value of learning rate increases the learning speed but decreases the accuracy and vice versa. In addition, the sampling frequency of the entire system can influence the learning speed. Through this method, the estimation signal will be similar to the desired signal after some looping processes. After that, the real and imaginary values of the desired signal can be extracted from $w(k)$. Finally, the amplitude for harmonic and inter-harmonic signals can be calculated via the following formula:

$$
A_{n}=\sqrt{w_{n-1}^{2}+w_{n}^{2}}=\sqrt{A_{n} \cos \theta_{n}{ }^{2}+A_{n} \sin \theta_{n}{ }^{2}} .
$$

\section{Proposed Algorithm}

As discussed above, the amplitudes of the particular interharmonics are the key values to determine the severity of the flicker level. Therefore, the proposed algorithm utilizes the ADALINE as the amplitudes detector for the fundamental component and interharmonics component. The design of the ADALINE for CFD is shown in Figure 4. After that, the particular amplitudes are substituted into (22) and (23) for determining the maximum and minimum of the fluctuation voltage. Next, the relative fluctuation voltage $(\Delta v / v)$ is calculated via (24). If the percentage of $\Delta v / v$ is greater than $0.25 \%$, critical flicker will be detected. Block diagram of the proposed algorithm is shown in Figure 5.

\section{Simulation Results}

The proposed algorithm is developed, configured, and simulated in MATLAB Simulink. The learning rate of the ADALINE is 0.01 . The simulation work is separated into 3 parts. The first part is to determine the most suitable sampling frequency for the ADALINE algorithm. Next, the critical flicker signal with noiseless condition is analyzed. Lastly, the critical flicker signal with signal noise ratio (SNR) of 30 10 dB condition is analyzed. Subsequently, based on IEC standard 
TABLE 1: Data analysis for the response waveforms obtained from the fundamental voltage via ADALINE.

\begin{tabular}{|c|c|c|c|c|c|}
\hline Number & Sampling frequency $(\mathrm{Hz})$ & Rise time (s) & Overshoot (\%) & Settling time (s) & Condition \\
\hline 1 & 51200 & 0.06 & 44.64 & 1 & Underdamped \\
\hline 2 & 25600 & 0.07 & 27.64 & 0.5 & Underdamped \\
\hline 3 & 12800 & 0.1 & 4.11 & 0.25 & Optimum \\
\hline 4 & 6400 & 0.57 & 0 & 0.57 & Overdamped \\
\hline 5 & 3200 & 1.08 & 0 & 1.08 & Overdamped \\
\hline 6 & 1600 & 2 & 0 & 2 & Overdamped \\
\hline
\end{tabular}

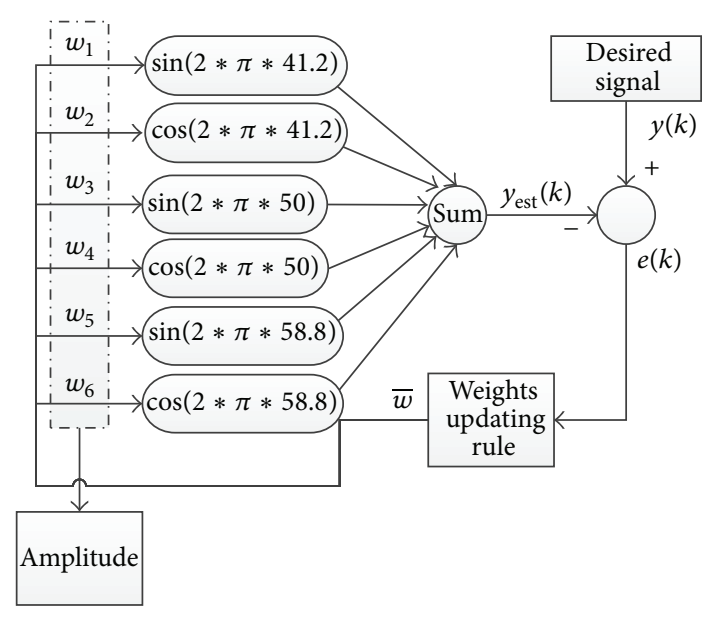

FIGURE 4: Block diagram of the ADALINE for critical flicker detection.

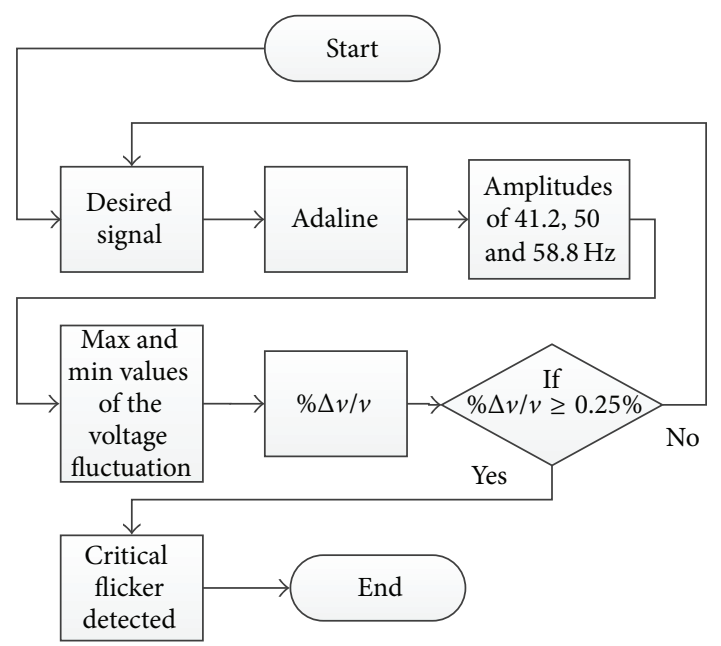

FIGURE 5: Block diagram for the proposed algorithm.

[3], the formula of the critical voltage flicker shown as follows will be used in the simulation work:

$$
\begin{aligned}
u(t)= & V_{1} \times \sqrt{2} \sin \left(2 \pi f_{1} t\right) \\
& \times\left\{1+\frac{\Delta v / v}{100}(0.5) \sin \left(2 \pi f_{f} t\right)\right\},
\end{aligned}
$$

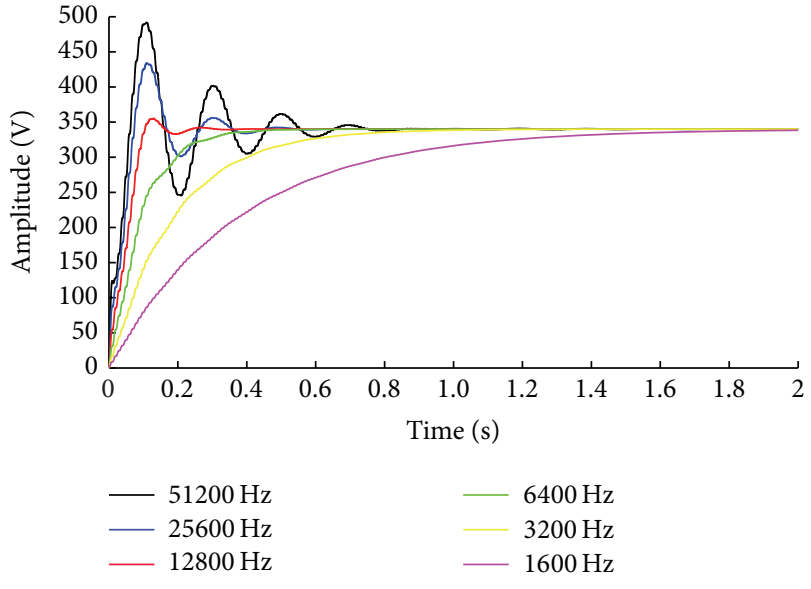

FIGURE 6: Response waveforms obtained from the fundamental voltage via ADALINE.

where $V_{1}$ is the supplied voltage (rms), $f_{1}$ is the fundamental frequency, $f_{f}$ is the flicker frequency, and $\Delta v / v$ is the relative fluctuation voltage.

Based on the equation above, $V_{1}, f_{1}, f_{f}$, and $\Delta v / v$ are configured as $240 \mathrm{~V}, 50 \mathrm{~Hz}, 8.8 \mathrm{~Hz}$, and $0.25 \%$, respectively.

Part 1: Sampling Frequency of the ADALINE Algorithm. The critical flicker waveform (29) is analyzed via ADALINE algorithm with various sampling frequencies from $1600 \mathrm{~Hz}$ to $51200 \mathrm{~Hz}$. The response waveforms obtained from the fundamental voltage are shown in Figure 6. Ideally, the steady state value for the fundamental voltage is $340 \mathrm{~V}$. Based on the aforementioned response waveforms, the sampling frequencies of $51200 \mathrm{~Hz}$ and $25600 \mathrm{~Hz}$ are considered as underdamped condition. Meanwhile, overdamped condition is represented by response waveforms for sampling frequencies of $6400 \mathrm{~Hz}$, $3200 \mathrm{~Hz}$, and $1600 \mathrm{~Hz}$. Table 1 shows the data analysis for the response waveforms obtained from the fundamental voltage via ADALINE, as shown in Figure 6. Subsequently, the sampling frequency of $12800 \mathrm{~Hz}$ is considered as optimum sampling frequency as it is able to operate the ADALINE with finest rise time, overshoot, and settling time. Therefore, the sampling frequency of $12800 \mathrm{~Hz}$ is justified to be used later in both simulation and experiment works.

Part 2: Critical Voltage Flicker Generation (Noiseless). The critical flicker waveform generated from (29) is shown in Figure 7. The zoom-in version of the critical flicker waveform 


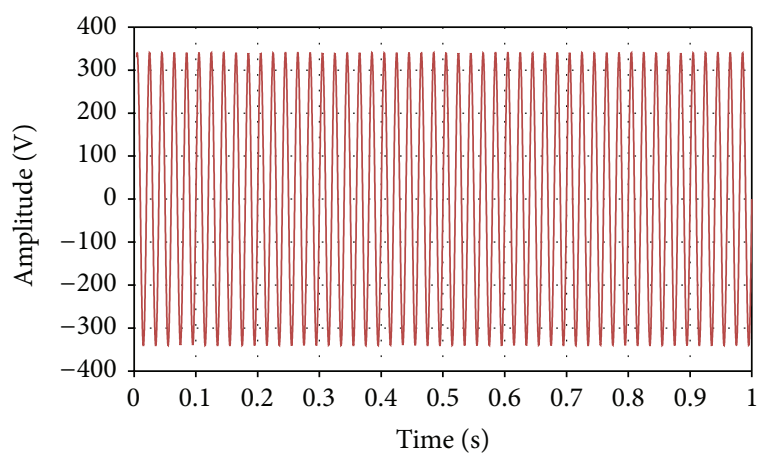

(a)

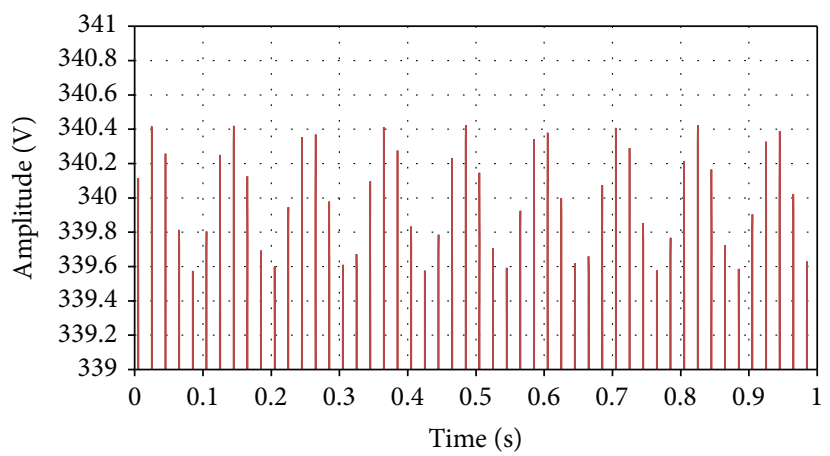

(b)

FIGURE 7: Critical flicker waveform (29): (a) zoom-out version and (b) zoom-in version.

TABLE 2: Summary of data analysis for the proposed algorithm (Simulation).

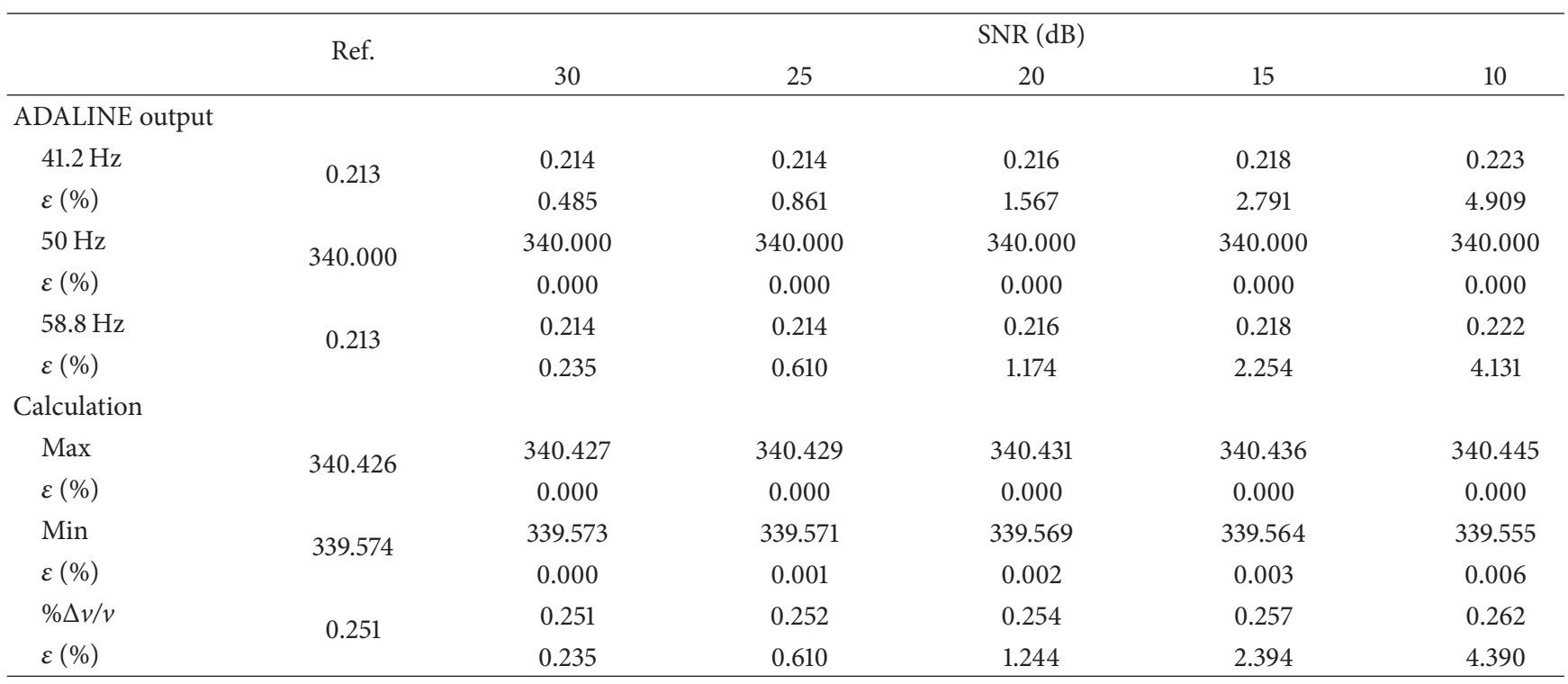

is shown in Figure 7(b). Based on Figure 7, the voltage waveform is fluctuated between 340.426 and $339.574 \mathrm{~V}$. Therefore the $\Delta v$ is $0.852 \mathrm{~V}$ and the relative $\Delta v / v$ is $0.25 \%$.

For the proposed algorithm, the output of the ADALINE for critical flicker waveform (Figure 7) is $0.213,340$, and $0.213 \mathrm{~V}$ for $41.2,50$, and $58.8 \mathrm{~Hz}$, respectively. The values of $0.213,340$, and $0.213 \mathrm{~V}$ that represent $\alpha_{3}, \alpha_{1}$, and $\alpha_{2}$ are substituted into (22) and (23). The maximum and minimum amplitudes values based on calculation are 340.426 and 339.574 V. The obtained maximum and minimum amplitudes are proven to be similar as the values obtained in the simulation work (Figure 7).

Part 3: Voltage Flicker Generation (with Signal Noise Ratio (SNR) of 30 10 dB). The robustness of the proposed algorithm is further analyzed in this part. The critical flicker waveform (equation (29)) is added with SNR of $30 \mathrm{~dB}$ to $10 \mathrm{~dB}$. SNR of $30 \mathrm{~dB}$ is able to simulate the noise level for practical measurement [30]. Figure 8 shows the aforementioned critical flicker waveform with SNR of $30 \mathrm{~dB}$ and $10 \mathrm{~dB}$. Critical flicker waveform in Figure 8 with SNR of $10 \mathrm{~dB}$ is more noisy than
$30 \mathrm{~dB}$ as the value of SNR is inverse proportional with the noise level. The performance index $(\varepsilon)$ is utilized in this simulation for measuring the accuracy of the detection which is calculated by

$$
\varepsilon=\frac{\mid \text { reference }- \text { measurement } \mid}{\text { reference }} \times 100 \%,
$$

where the reference value is the actual value (without noise) and the measurement is the measurement with SNR. In this case, small value of $\varepsilon$ represents higher accuracy of the measurement and vice versa. The summary of data analysis for the proposed algorithm is listed in Table 2. The $\varepsilon$ of the analysis is not more than $5 \%$. Therefore, the proposed algorithm has potential to be applied in any threatening power quality condition.

\section{Experimental Results}

The experimental setup (Figure 9) for CFD is conducted by using a programmable AC source model 6590. The flicker waveform with $8.8 \mathrm{~Hz}$ flicker frequency is generated by 
TABLE 3: Summary of data analysis for the proposed algorithm (experimental).

\begin{tabular}{|c|c|c|c|c|c|c|c|c|c|}
\hline \multirow{2}{*}{ Amplitude level (V) } & \multicolumn{3}{|c|}{ ADALINE output } & \multicolumn{4}{|c|}{ Calculation } & \multirow{2}{*}{ Fluke (Pinst) } & \multirow{2}{*}{ Accuracy } \\
\hline & $41.2 \mathrm{~Hz}$ & $50 \mathrm{~Hz}$ & $58.8 \mathrm{~Hz}$ & $\operatorname{Max}(22)$ & $\operatorname{Min}(23)$ & $\% \Delta v / v(24)$ & Critical Flicker & & \\
\hline 239.00 & 0.20 & 336.10 & 0.43 & 336.73 & 335.47 & 0.37 & YES & 4.22 & $100 \%$ \\
\hline 239.10 & 0.18 & 336.10 & 0.39 & 336.68 & 335.52 & 0.34 & YES & 3.52 & $100 \%$ \\
\hline 239.20 & 0.27 & 336.20 & 0.27 & 336.74 & 335.66 & 0.32 & YES & 2.50 & $100 \%$ \\
\hline 239.30 & 0.29 & 336.30 & 0.27 & 336.86 & 335.74 & 0.33 & YES & 2.05 & $100 \%$ \\
\hline 239.40 & 0.31 & 336.40 & 0.19 & 336.90 & 335.90 & 0.30 & YES & 1.55 & $100 \%$ \\
\hline 239.50 & 0.08 & 336.50 & 0.25 & 336.83 & 336.17 & 0.19 & NO & 0.90 & $100 \%$ \\
\hline 239.60 & 0.21 & 336.50 & 0.13 & 336.84 & 336.16 & 0.20 & NO & 0.61 & $100 \%$ \\
\hline 239.70 & 0.25 & 336.60 & 0.05 & 336.90 & 336.30 & 0.18 & $\mathrm{NO}$ & 0.39 & $100 \%$ \\
\hline 239.80 & 0.18 & 336.70 & 0.12 & 337.00 & 336.40 & 0.18 & NO & 0.10 & $100 \%$ \\
\hline 239.90 & 0.10 & 336.70 & 0.16 & 336.96 & 336.44 & 0.16 & NO & 0.03 & $100 \%$ \\
\hline 240.00 & 0.14 & 336.80 & 0.17 & 337.11 & 336.49 & 0.18 & NO & 0.00 & $100 \%$ \\
\hline
\end{tabular}

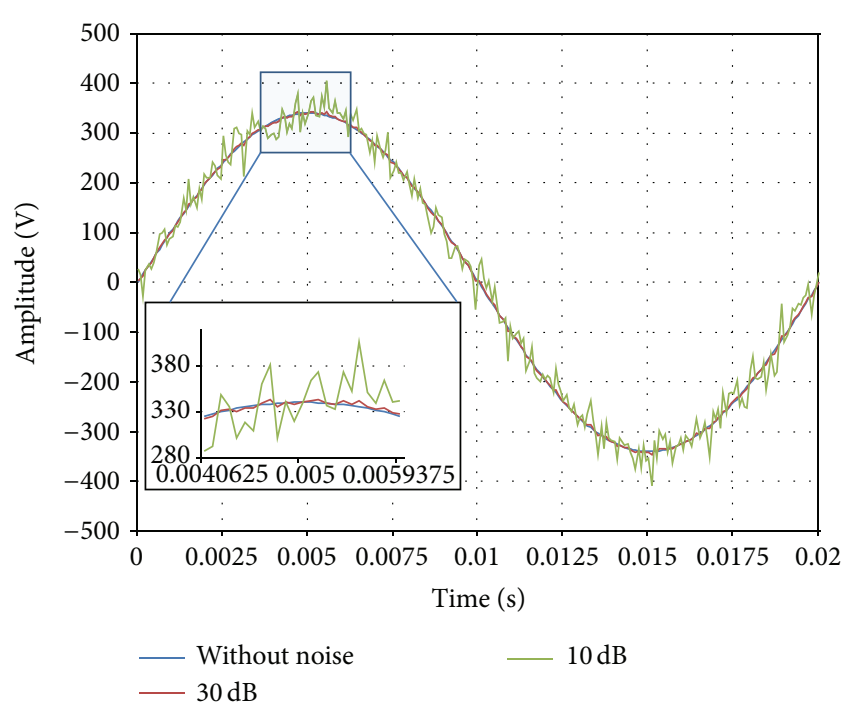

FIGURE 8: Critical flicker waveform of (29) with SNR of $30 \mathrm{~dB}$ and $10 \mathrm{~dB}$.

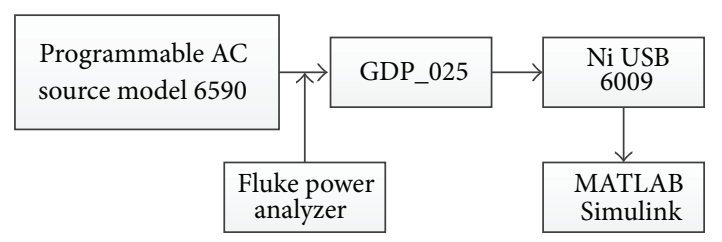

Figure 9: Configuration block for the experimental work.

aforementioned programmable AC. In order to evaluate the robustness of the proposed algorithm, various amplitudes of flicker are investigated. Typical Fluke power analyzer $\left(P_{\text {inst }}\right)$ is employed as the benchmarking tool. Ni USB 6009 and Gw Instek differential probe GDP_025 are utilized as data acquisition. The sampling frequency of the experimental work is $12800 \mathrm{~Hz}$ with fundamental frequency of $50 \mathrm{~Hz}$. The learning rate of the ADALINE is 0.01. Finally, the data is exported to MATLAB Simulink to be further analyzed by the proposed algorithm.

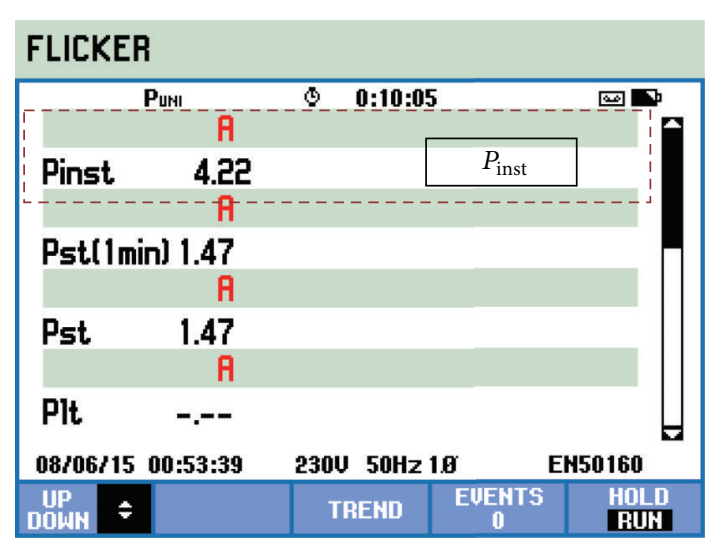

FIGURE 10: Fluke power analyzer's results for flicker voltage amplitude (rms) of $239 \mathrm{~V}$.

The voltage supply (rms) is $240 \mathrm{~V}$. After that, the voltage waveform is interrupted by an envelope pulse $(8.8 \mathrm{~Hz})$ which is generated by the programmable AC source model 6590 . The amplitude of the envelope pulse is varied voltage ( $r m s$ ) from 239 to $240 \mathrm{~V}$ with increasing step size of $0.1 \mathrm{~V}$. Therefore, 11 sets of test are conducted. Based on Table 3, the flicker waveform is analyzed by the ADALINE. After that, the outputs of the ADALINE are substituted into (22), (23), and (24) accordingly for determining the maximum, minimum, and relative fluctuation voltage, respectively. If the value of relative fluctuation voltage is more than $0.25 \%$, the critical flicker is detected. At the same time, the flicker waveforms are analyzed by the typical Fluke power analyzer $\left(P_{\text {inst }}\right)$ (Figure 10). $P_{\text {inst }}$ is utilized as the suitable benchmarking parameter in this experimental part. According to IEC flickermeter's calibration procedure, $P_{\text {inst }}$ must show 1 when $8.8 \mathrm{~Hz}$ sinusoidal voltage with relative fluctuation voltage $0.25 \%$ is injected to the flickermeter [31]. Therefore, when $P_{\text {inst }}$ is more than or equal to 1 , critical flicker is detected. Figure 11 shows the data analysis for the experimental work. The proposed algorithm is able to detect the critical flicker accurately. In a nutshell, the accuracy of the proposed algorithm is similar, as compared with the typical Fluke power analyzer. 


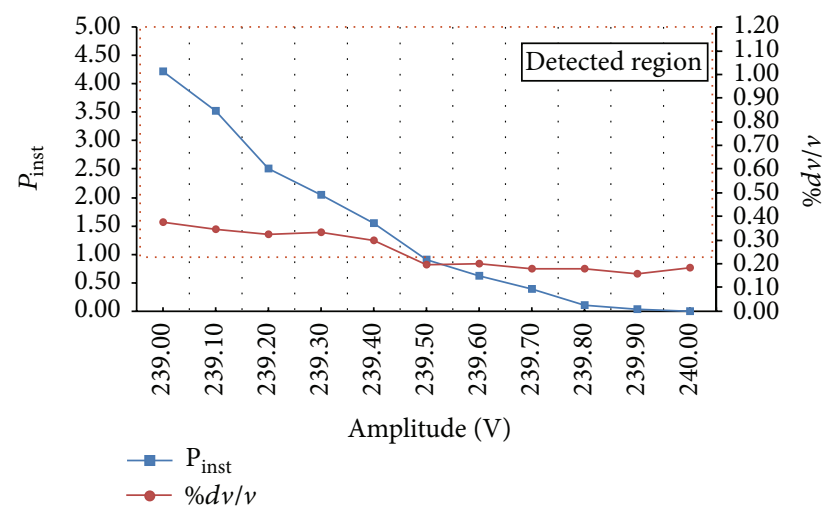

FIGURE 11: Data analysis for the experimental work.

\section{Conclusion}

This paper has presented a simple predictive method of critical flicker detection algorithm for human health precaution based on amplitude of the particular interharmonics. The interrelationship between amplitude level for the particular interharmonics and critical flicker is explained and the related formulas are derived clearly in this paper. The significant findings obtained in this paper are the amplitudes of two particular interharmonics are able to identify the severity of the critical flicker. Based on the aforementioned findings, 41.2 and $58.8 \mathrm{~Hz}$ are summarized as the critical interharmonics for the critical flicker. After that, the amplitude of the aforementioned interharmonics are substituted into (22), (23), and (24) accordingly for determining the severity of the critical flicker. The robustness of the proposed algorithm is evaluated in both simulation and experimental works. Additionally, typical Fluke power analyzer $\left(P_{\text {inst }}\right)$ is utilized as benchmarking for the proposed algorithm. Finally, the accuracy of the proposed algorithm is similar, as compared to typical Fluke power analyzer. Last but not least, the proposed algorithm has potential to be applied in any crowded human places (such as office, shopping complex, and stadium) for human healthy precaution purpose.

\section{Conflict of Interests}

The authors declare that there is no conflict of interests regarding the publication of this paper.

\section{Acknowledgments}

This work was supported by the Putra Grouped Initiative Grant Scheme under Universiti Putra Malaysia (GP-IPB/ 2013/9412102) and Exploratory Research Gant Scheme under Ministry of Education, Malaysia (ERGS/1-2013/5527141).

\section{References}

[1] W. M. Grady and S. Santoso, "Understanding power system harmonics," IEEE Power Engineering Review, vol. 21, no. 11, pp. 8-11, 2001.
[2] T. Tayjasanant, W. Wang, C. Li, and W. Xu, "Interharmonicflicker curves," IEEE Transactions on Power Delivery, vol. 20, no. 2, pp. 1017-1024, 2005.

[3] Advanced Test Equipment Rentals, "Electromagnetic compatibility (EMC) - part 4-15: testing and measurement techniques -flickermeter-functional and design specifications," IEC 61000-4-15, Advanced Test Equipment Rentals, San Diego, Calif, USA, 2011.

[4] V. B. Virulkar and M. V. Aware, "Power system flicker analysis, modeling and prototype implementation," in Proceedings of the 38th Annual Conference on IEEE Industrial Electronics Society (IECON '12), pp. 5833-5839, IEEE, Québec, Canada, October 2012.

[5] G. Wiczynski, "Inaccuracy of short-term light flicker Pst indicator measuring with a flickermeter," IEEE Transactions on Power Delivery, vol. 27, no. 2, pp. 842-848, 2012.

[6] R. H. G. Tan and V. K. Ramachandaramurthy, "Tolerance analysis of flicker Pst short term perceptibility assessment for one minute observation time," in Proceedings of the IEEE International Power Engineering and Optimization Conference (PEOCO '12), pp. 281-284, Melaka, Malaysian, June 2012.

[7] D. Michel and G. de Preville, "Mixed topology for flicker mitigation," in Proceedings of the 2nd International Conference on Power Electronics, Machines and Drives (PEMD '04), vol. 1 of Conference Publication No. 498, pp. 253-257, IET, April 2004.

[8] M. Routimo, A. Mäkinen, M. Salo, R. Seesvuori, J. Kiviranta, and H. Tuusa, "Flicker mitigation with a hybrid compensator," IEEE Transactions on Industry Applications, vol. 44, no. 4, pp. 1227-1238, 2008.

[9] O. Boudebbouz, A. Boukadoum, and S. Leulmi, "Harmonic sequence impedances: a tool for the three-phase frequency scan technique," Arabian Journal for Science and Engineering, vol. 36, no. 7, pp. 1277-1286, 2011.

[10] A. Kessal, L. Rahmani, J.-P. Gaubert, and M. Mostefai, "Power factor corrector with a fast regulation and constant switching frequency," Arabian Journal for Science and Engineering, vol. 38, no. 3, pp. 651-659, 2013.

[11] C.-C. Shen and C.-H. Lin, "Chirp-encoded excitation for dualfrequency ultrasound tissue harmonic imaging," IEEE Transactions on Ultrasonics, Ferroelectrics, and Frequency Control, vol. 59, no. 11, 2012.

[12] B. Badrzadeh, M. Gupta, N. Singh, A. Petersson, L. Max, and M. Hogdahl, "Power system harmonic analysis in wind power plants part I: study methodology and techniques," in Proceedings of the IEEE Industry Applications Society Annual Meeting (IAS '12), pp. 1-11, Las Vegas, Nev, USA, October 2012.

[13] C.-S. Wang and M. J. Devaney, "Incandescent lamp flicker mitigation and measurement," IEEE Transactions on Instrumentation and Measurement, vol. 53, no. 4, pp. 1028-1034, 2004.

[14] J. Yong, T. Tayjasanant, W. Xu, and C. Sun, "Characterizing voltage fluctuations caused by a pair of interharmonics," IEEE Transactions on Power Delivery, vol. 23, no. 1, pp. 319-327, 2008.

[15] T. Keppler, N. R. Watson, J. Arrillaga, and C. Shiun, "Theoretical assessment of light flicker caused by sub- and interharmonic frequencies," IEEE Transactions on Power Delivery, vol. 18, no. 1, pp. 329-333, 2003.

[16] W. Xu, "Deficiency of the IEC flicker meter for measuring interharmonic-caused voltage flickers," in Proceedings of the IEEE Power Engineering Society General Meeting, vol. 3, pp. 2326-2329, June 2005.

[17] R. Langella, F. Liccardo, P. Marino, A. Testa, and M. Triggianese, "On the assessment of Light Flicker due to the interharmonic 
distortion produced by wind turbines," in Proceedings of the International Conference on Clean Electrical Power (ICCEP '07), pp. 529-535, IEEE, Capri, Italy, May 2007.

[18] Z. Dahai, X. Wilsun, and A. Nassif, "Flicker source identification by interharmonic power direction," in Canadian Conference on Electrical and Computer Engineering, pp. 549-552, Saskatoon, Canada, May 2005.

[19] P. S. Wright, "Short-time fourier transforms and Wigner-Ville distributions applied to the calibration of power frequency harmonic analyzers," IEEE Transactions on Instrumentation and Measurement, vol. 48, no. 2, pp. 475-478, 1999.

[20] A. R. Abdullah, G. Z. Peng, S. A. Ghani, and M. H. Jopri, "A new vector draft method for harmonic source detection at point of common coupling," in Proceedings of the IEEE 8th International Power Engineering and Optimization Conference (PEOCO '14), pp. 110-114, Langkawi, Malaysia, March 2014.

[21] L. Coppola, Q. Liu, S. Buso, D. Boroyevich, and A. Bell, "Wavelet transform as an alternative to the short-time Fourier transform for the study of conducted noise in power electronics," IEEE Transactions on Industrial Electronics, vol. 55, no. 2, pp. 880-887, 2008.

[22] M. Verma and R. Sindal, "Simulation and analysis of DIT FFT algorithm for spartan 3 FPGA," in Proceedings of the 3rd International Conference on Communication Systems and Network Technologies (CSNT '13), pp. 721-726, IEEE, Gwalior, India, April 2013.

[23] H.-C. Lin, "Inter-harmonic identification using groupharmonic weighting approach based on the FFT," IEEE Transactions on Power Electronics, vol. 23, no. 3, pp. 1309-1319, 2008.

[24] G. W. Chang, C. I. Chen, Y. J. Liu, and M. C. Wu, "Measuring power system harmonics and interharmonics by an improved fast Fourier transform-based algorithm," IET Generation, Transmission \& Distribution, vol. 2, no. 2, pp. 193-201, 2008.

[25] M. Korkali and A. Abur, "Robust fault location using leastabsolute-value estimator," IEEE Transactions on Power Systems, vol. 28, no. 4, pp. 4384-4392, 2013.

[26] P. K. Ray and B. Subudhi, "Ensemble-kalman-filter-based power system harmonic estimation," IEEE Transactions on Instrumentation and Measurement, vol. 61, no. 12, pp. 3216-3224, 2012.

[27] M. Qasim, P. Kanjiya, and V. Khadkikar, "Optimal current harmonic extractor based on unified ADALINEs for shunt active power filters," IEEE Transactions on Power Electronics, vol. 29, no. 12, pp. 6383-6393, 2014.

[28] A. M. Alkandari, S. A. Soliman, and A. H. Mantwy, "Simulated annealing optimization algorithm for electric power systems quality analysis: harmonics and voltage flickers," in Proceedings of the 12th International Middle East Power System Conference (MEPCON '08), pp. 287-293, IEEE, Aswan, Egypt, March 2008.

[29] M. I. Marei, E. F. El-Saadany, and M. M. A. Salama, "Envelope tracking techniques for flicker mitigation and voltage regulation," IEEE Transactions on Power Delivery, vol. 19, no. 4, pp. 1854-1861, 2004.

[30] M. V. Chilukuri, P. K. Dash, and K. P. Basu, “Time-frequency based pattern recognition technique for detection and classification of power quality disturbances," in Proceedings of the IEEE Region 10 Conference: Analog and Digital Techniques in Electrical Engineering (TENCON '04), vol. 3, pp. C260-C263, November 2004.
[31] P. Clarkson and P. S. Wright, “The calibration of IEC standard flickermeters using complex modulated signals," IEEE Transactions on Instrumentation and Measurement, vol. 58, no. 4, pp. 1017-1022, 2009. 


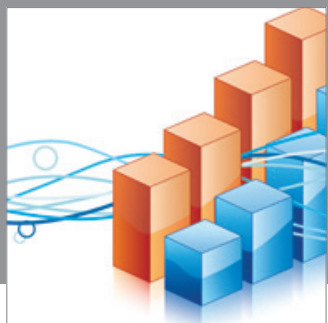

Advances in

Operations Research

mansans

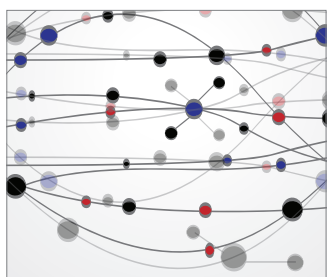

The Scientific World Journal
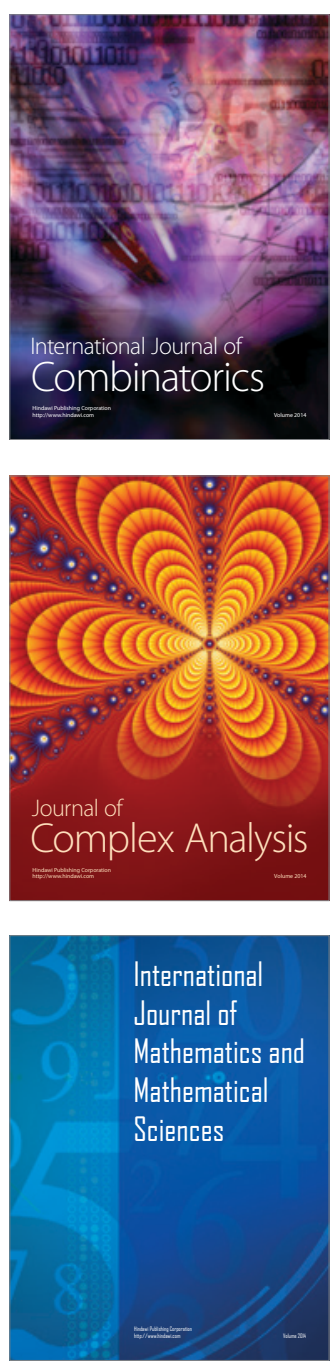
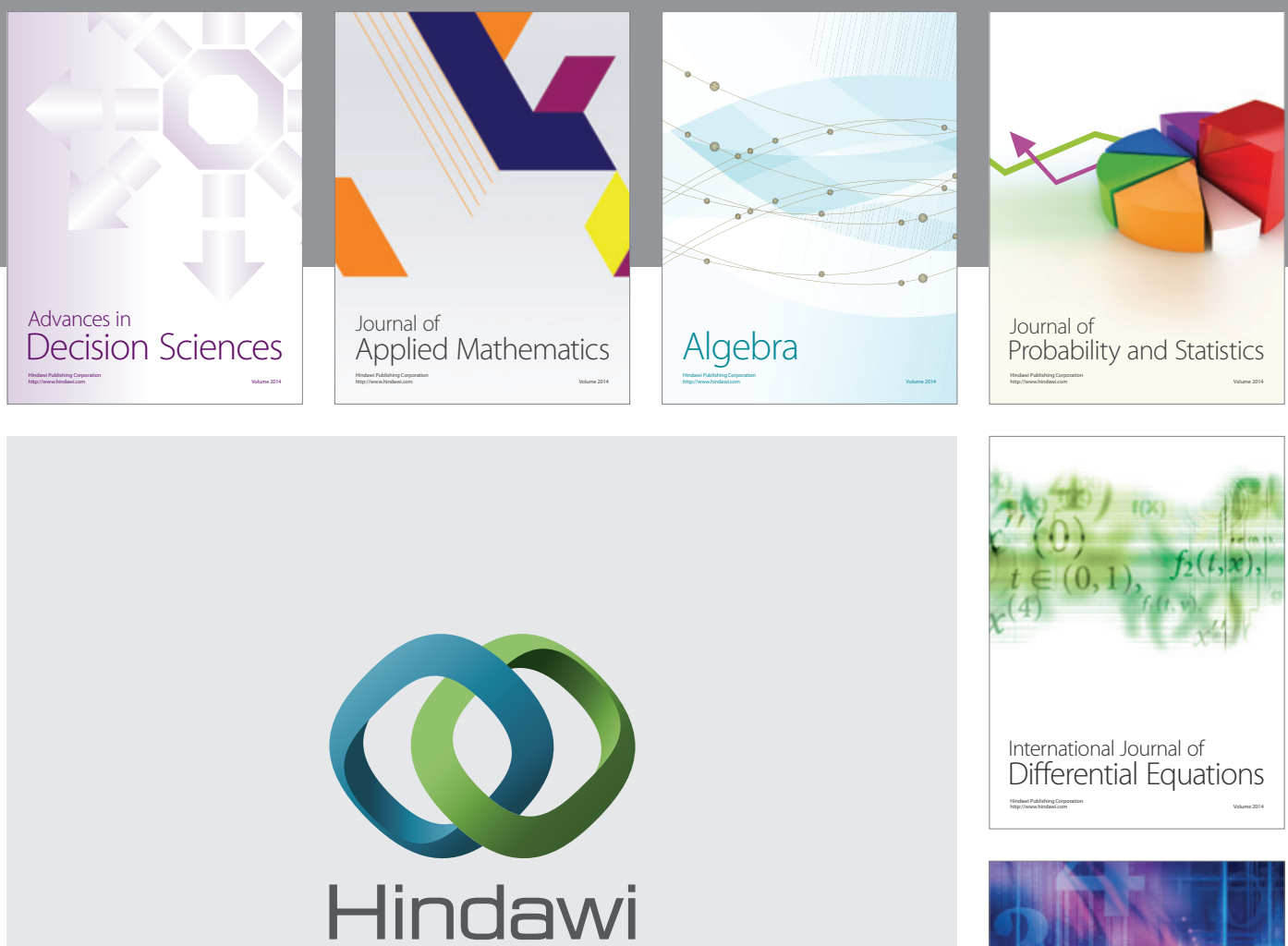

Submit your manuscripts at http://www.hindawi.com
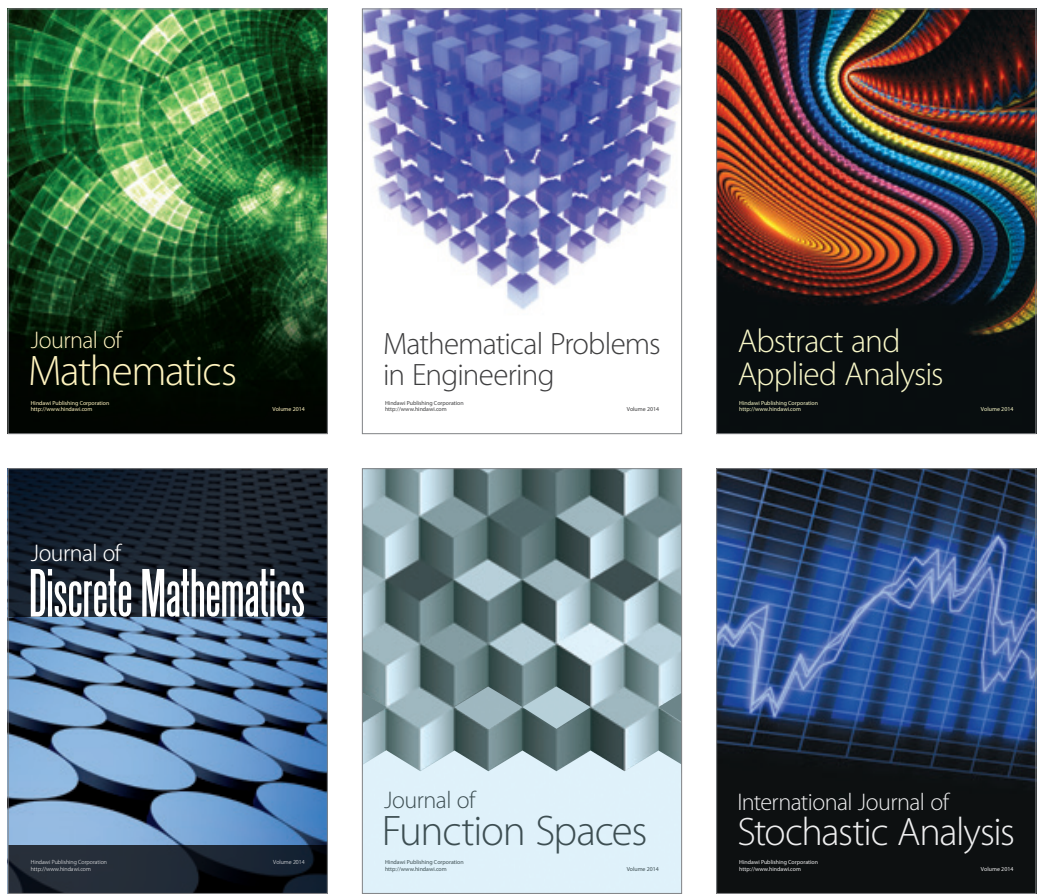

Journal of

Function Spaces

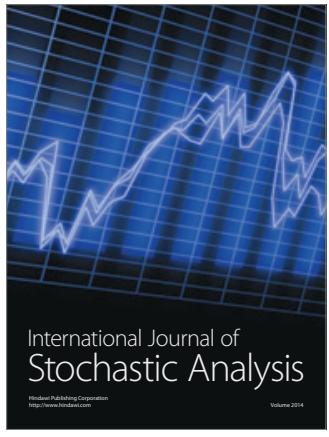

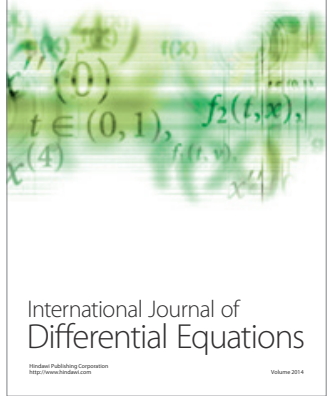
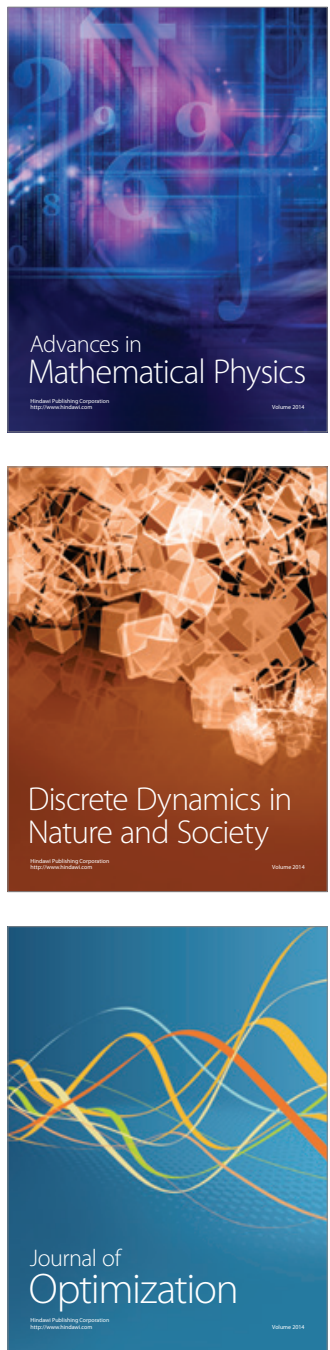